\title{
What soil properties regulate respiration rate as an indicator of soil health?
}

\section{Mostafa Ibrahim¹, Michael Thompson¹, Matt Liebman¹, and Matt Helmers² \\ ${ }^{1}$ Agronomy Department, lowa State University \\ ${ }^{2}$ Agricultural and Biosystems Engineering Department, lowa State University}

- The term soil health refers to a holistic perspective on how a soil functions in the agricultural ecosystem, with particular emphasis on biological processes.

- Healthy soils are resilient to external impacts that might negatively affect the productivity and stability of the soil ecosystem.

\section{Objective}

To assess the relationship between short-term $\mathrm{CO}_{2}$ evolution (soil respiration) (an indicator of soil health) and other soil properties (e.g., organic carbon (OC), total nitrogen (TN), particulate organic matter (POM), and water-extractable organic carbon and nitrogen (WEOC and WEON) under perennial and annual cropping systems

\section{Materials \& Methods}

The experiment was established in 2008 near ISU. All plots are tile drained and receive no tillage.

The experimental treatments: continuous corn (CC), continuous corn with a rye cover crop (CCW), unfertilized reconstructed multispecies prairie $(P)$, and fertilized reconstructed multispecies prairie (PF).

Soil sampling: Two composite samples from each plot were collected from the $0-15 \mathrm{~cm}$ depth at four times, i.e., in April and November in both 2016 and 2017.

Soil analyses: Soil properties were determined, e.g., soil $\mathrm{CO}_{2}$ respiration using the Solvita technique (Fig. 1) OC, TN, POM, WEOC, and WEON.

Field plot layout
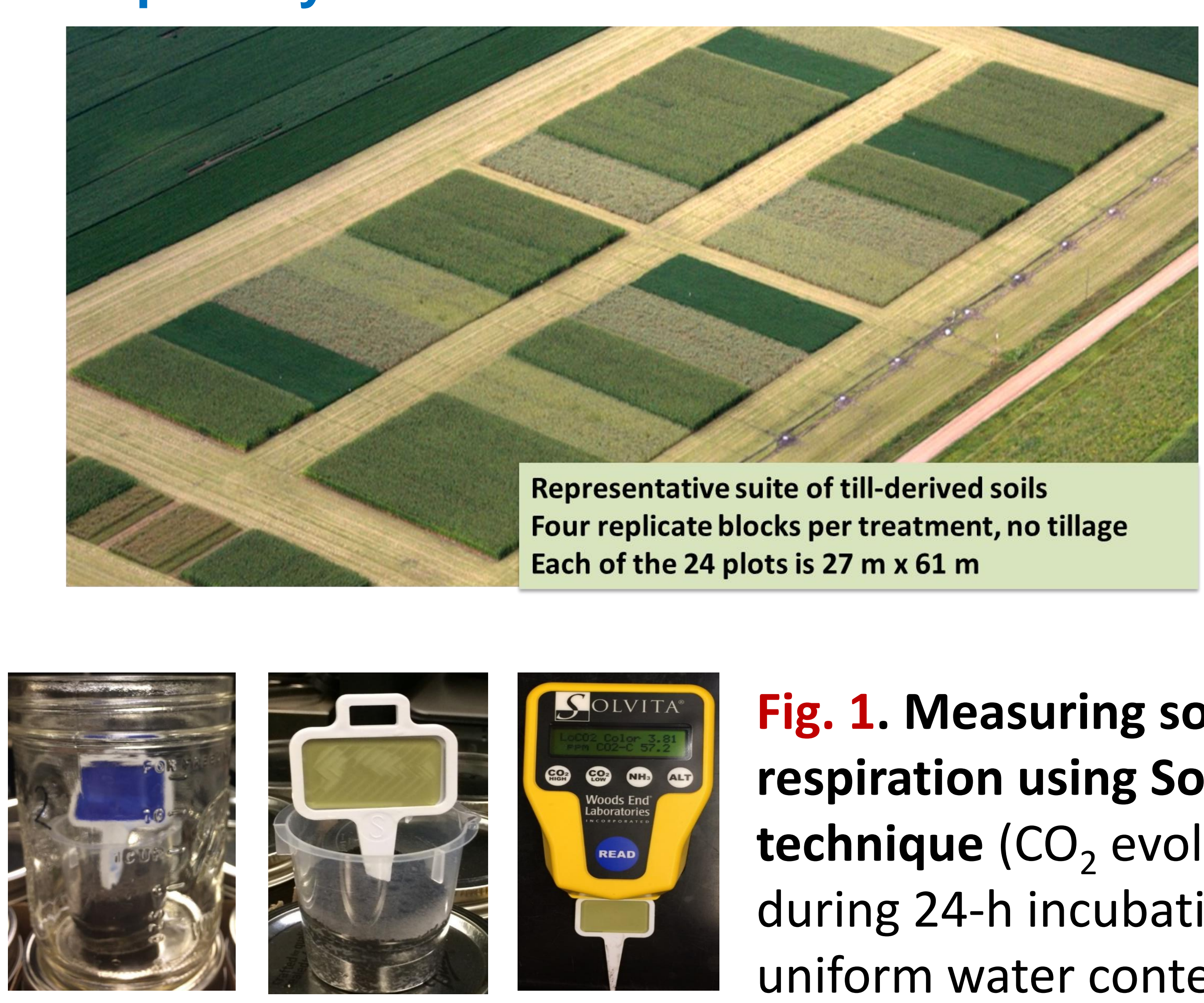

Fig. 1. Measuring soil $\mathrm{CO}_{2}$ respiration using Solvita technique $\left(\mathrm{CO}_{2}\right.$ evolved during 24-h incubation at uniform water content)

Soil health Index: We used the Haney soil health $=\left(\mathrm{CO}_{2} / 10+\mathrm{WEOC} / 100+\mathrm{WEON} / 10\right)$

\section{Results}

Particulate organic matter (POM) in perennial cropping systems (P and PF) was significantly greater than that in annual cropping systems (CC and CCW) (Fig. 2) (Both years and seasons were pooled).

$>$ Soil $\mathrm{CO}_{2}$ respiration in perennial crops (P and PF) was significantly greater than that in annual crops (CC and CCW) (Fig. 3). (Both years and seasons were pooled)

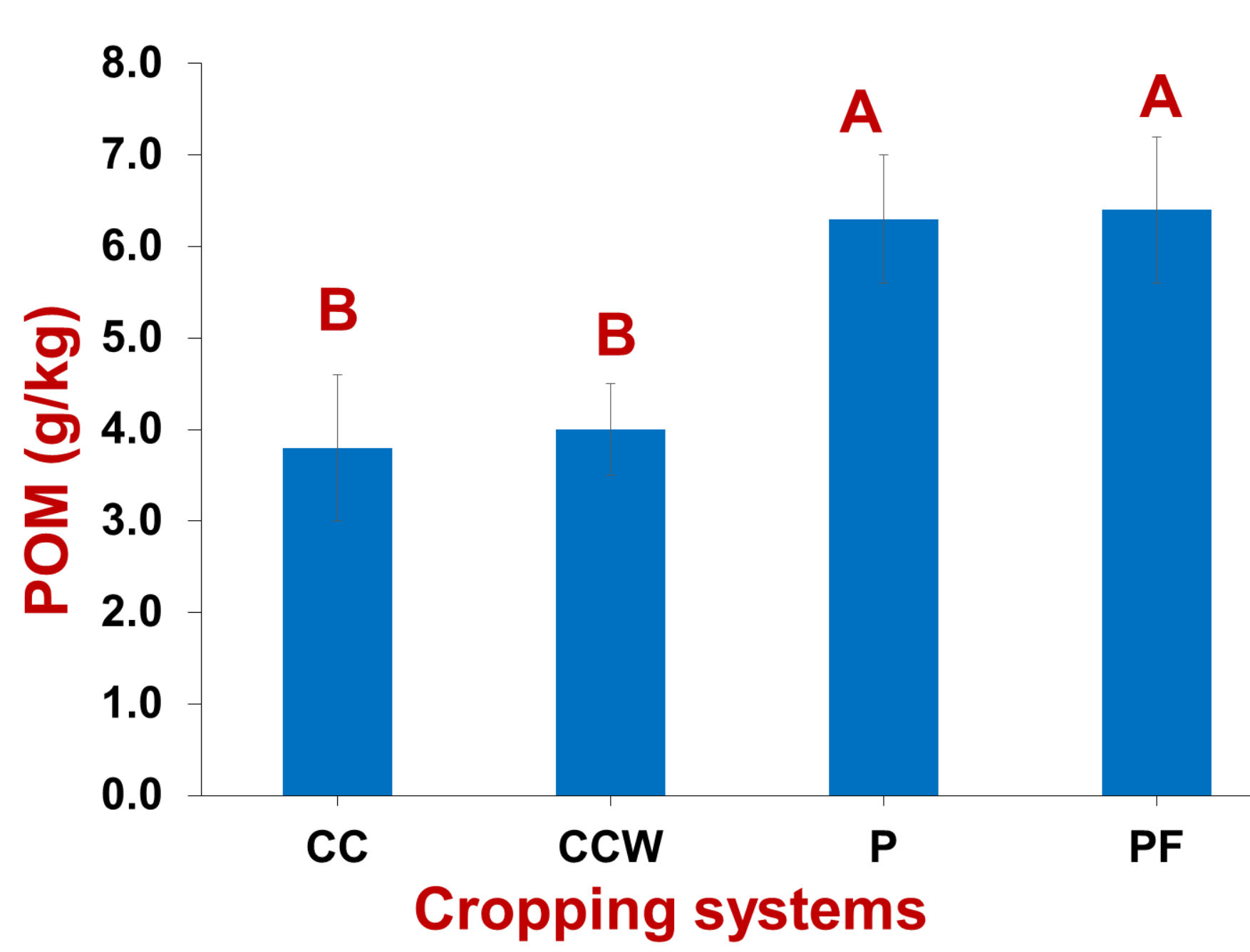

Fig. 2. Particulate organic matter (POM) concentration in perennial and annual crops

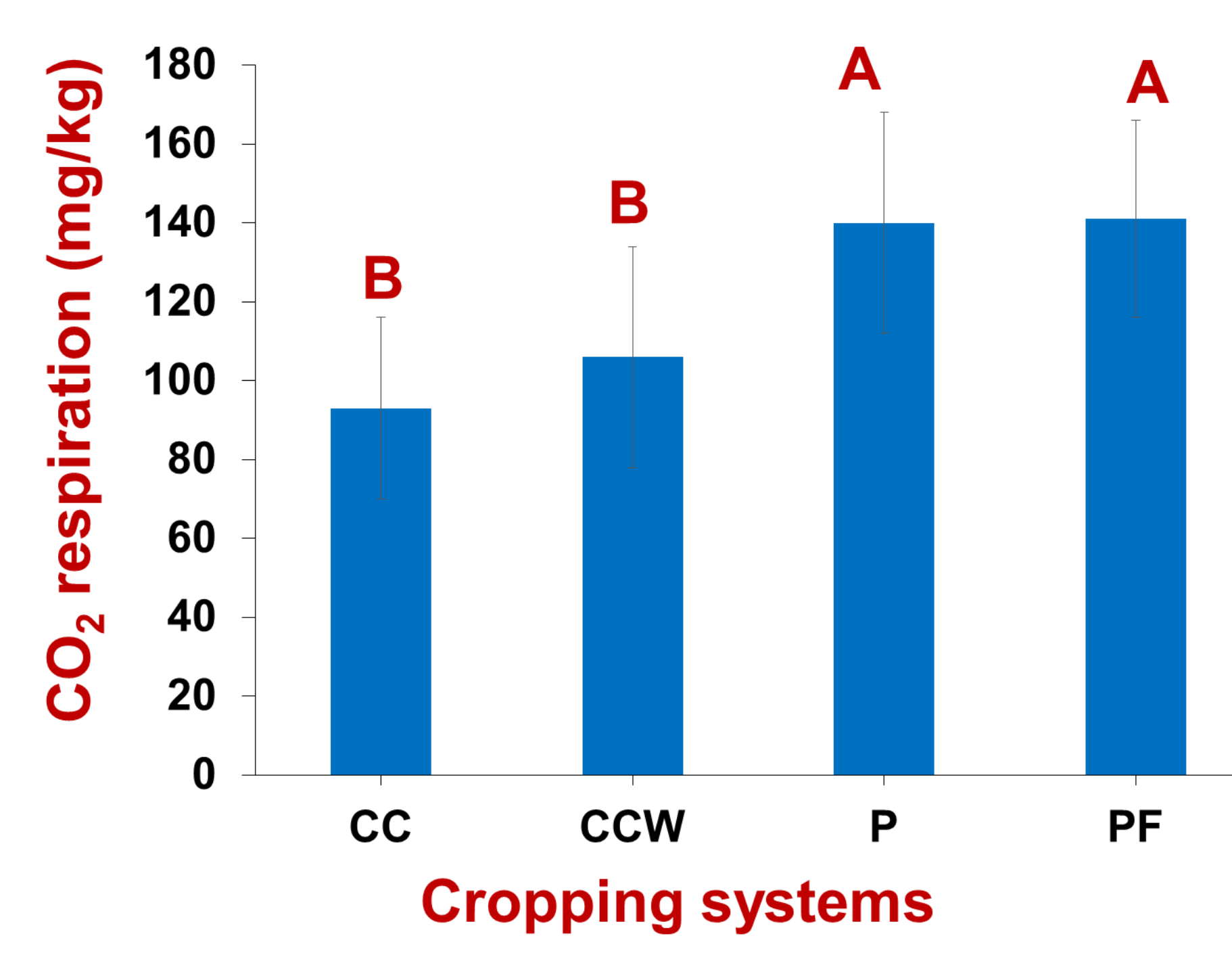

Fig. 3. Soil $\mathrm{CO}_{2}$ respiration in perennial and annual crops.
> Regulators of respiration. We explored the possibilities that the 24-h respiration rate might be regulated by POM-C, water-extractable $\mathrm{C}$, soil organic $\mathrm{C}$, total soil $\mathrm{N}$, soil clay, and water-extractable organic $\mathrm{N}$. Only POM-C and water-extractable $\mathrm{C}$ were found to be significantly related to $\mathrm{CO}_{2}-\mathrm{C}$ respired.

Over all treatments, years, and seasons: Table 1. Parameter estimates and effect tests (2-way ANOVA) (64 observations - pooling treatments, years, and seasons)

24-h $\mathrm{CO}_{2}$ respiration was significantly related to both POM-C and WEOC (Table 1)

$>$ When the years and seasons were considered separately, however, $\mathrm{CO}_{2}$ respiration was significantly related only to POM-C and in three of the four sampling times (Table 2).

\begin{tabular}{|l|c|c|c|c|}
\hline Term & $\begin{array}{c}\text { Parameter } \\
\text { Estimate }\end{array}$ & Std Error & F Ratio & Prob $>$ F \\
\hline Intercept & 6.6 & 16.4 & & \\
\hline POM-C $\left(\mathrm{g} \mathrm{C} \mathrm{kg}^{-1}\right)$ & 25.4 & 5.8 & 18.83 & $<0.0001$ \\
\hline WEOC $\left(\mathrm{mg} \mathrm{kg}^{-1}\right)$ & 0.24 & 0.06 & 18.49 & $<0.0001$ \\
\hline
\end{tabular}

Table 2. Two-way ANOVA model for each year and season ( $\mathrm{n}=16$ for each) $\mathrm{CO}_{2}-\mathrm{C}\left(\mathrm{mg} \mathrm{kg}^{-1}\right)=$ POM-C $\left(\mathrm{g} \mathrm{C} \mathrm{kg}^{-1}\right)+$ WEOC $\left(\mathrm{mg} \mathrm{kg}^{-1}\right)$ Param. Est. F Ratio Prob $>\mathrm{F}$ Spring 2016 POM- C ( kg-1 $\left.^{-1}\right)$ WEOC (mg kg-1) Fall 2016

POM-C $\left(\mathrm{g} \mathrm{kg}^{-1}\right)$ WEOC $\left(\mathrm{mg} \mathrm{kg}^{-1}\right)$

Spring 2017 POM-C $\left(\mathrm{g} \mathrm{kg}^{-1}\right)$ WEOC $\left(\mathrm{mg} \mathrm{kg}^{-1}\right)$ Fall 2017 POM-C (g kg-1) WEOC $\left(\mathrm{mg} \mathrm{kg}^{-1}\right)$

\begin{tabular}{|c|c|c|c|}
\hline $\mathrm{R}^{2}=0.47, \mathrm{P}=0.0152$ & & & \\
\hline & 33.25 & 5.88 & $0.031^{*}$ \\
\hline $\mathrm{R}^{2}=0.30, \mathrm{P}=0.0948$ & 0.26 & 2.44 & 0.142 \\
\hline & 23.01 & 2.17 & 0.165 \\
\hline $\mathrm{R}^{2}=0.67, \mathrm{P}=0.0007$ & 0.11 & 0.15 & 0.709 \\
\hline & & & \\
\hline & 28.97 & 24.55 & $0.0003^{*}$ \\
\hline $\mathrm{R}^{2}=0.74, \mathrm{P}=0.0002$ & 0.05 & 0.21 & 0.6530 \\
& & & \\
& 41.72 & 24.82 & $0.0003^{*}$ \\
\hline & -0.02 & 0.02 & 0.8981 \\
\hline
\end{tabular}

Haney Soil Health Index (SHI):

The soil health index for the perennial treatments ( $P$ and PF) was significantly higher than that of the annual treatments (CC and CCW) (Fig. 4). This result corresponds with the strong weighting of 24-h respired $\mathrm{CO}_{2}$ in the Soil Health Index.

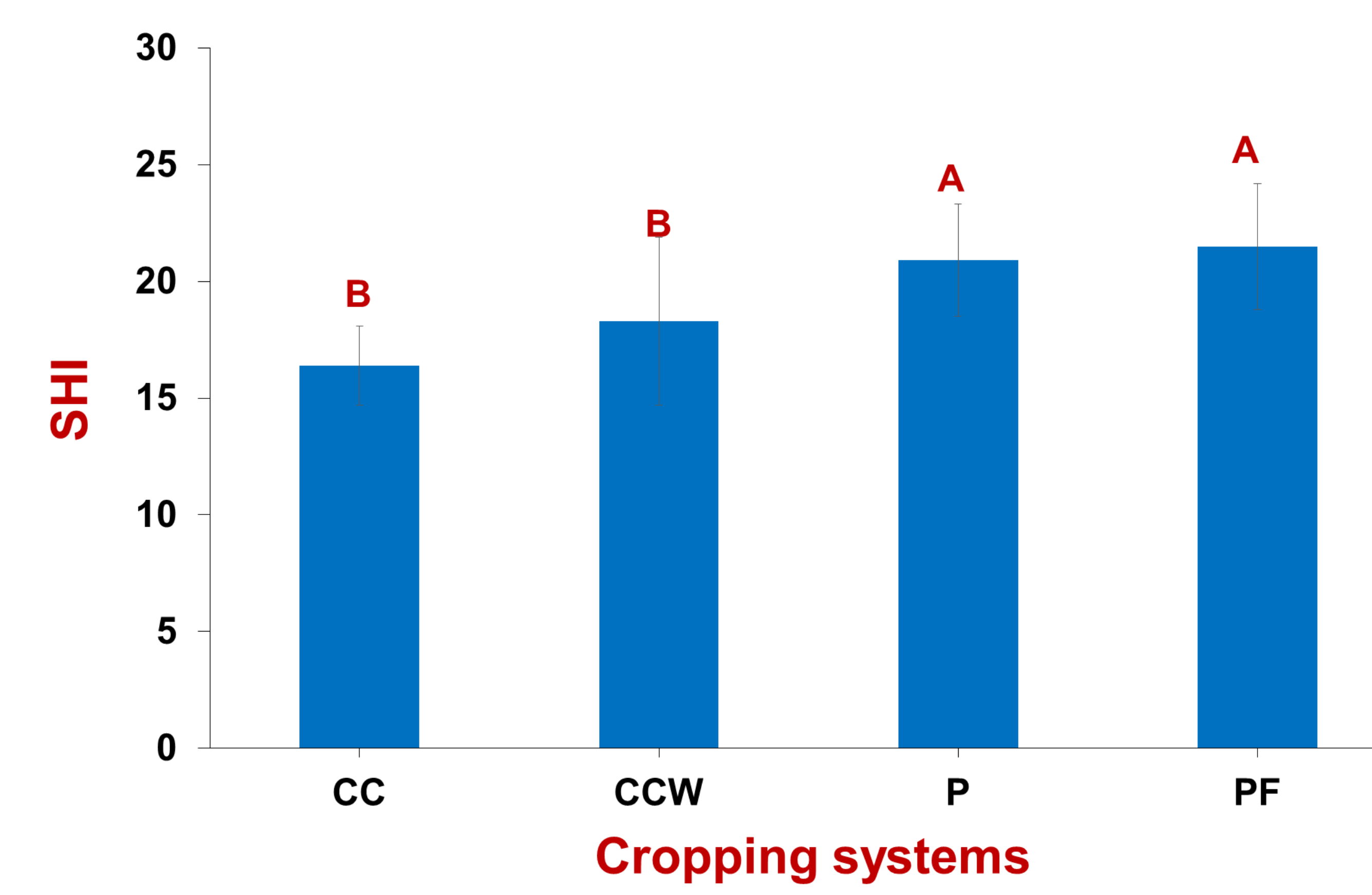

Cropping systems

Fig. 4. Haney Soil Health Index (SHI) under four biofuel cropping systems

\section{Conclusions}

Compared to annual bioenergy crops (CC and CCW treatments), soil under the perennial bioenergy crops (P and PF treatments) had significantly greater concentrations of $\mathrm{POM}$, greater $\mathrm{CO}_{2}$ respiration rates, and higher soil health indices. POM carbon and water-extractable carbon had statistically significant impacts on $\mathrm{CO}_{2}$ respiration, but other parameters tested (non-POM organic $\mathrm{C}$, total N, water-extractable $\mathrm{N}$, and clay) did not.

\section{Acknowledgments}

We thank the Leopold Center for Sustainable Agriculture and the lowa Nutrient Research Center for supporting this work. 